\title{
EXPLICANDO UMA EXPLICAÇÃO
}

\author{
Isabel Martins ${ }^{1}$ \\ Jon Ogborn ${ }^{2}$ \\ Gunther Kress ${ }^{3}$ \\ Apoio parcial do CNPq
}

\section{Resumo}

Este artigo apresenta e discute um referencial para análise de episódios explicativos na sala de aula de ciências desenvolvido a partir de análises de contribuições teóricas nas áreas de Educação em Ciências, Linguística, Ciência Cognitiva, e de investigações empíricas envolvendo observação de aulas de ciências em escolas secundárias da região da Grande Londres. As categorias propostas relacionam: a criação de diferenças que motivam explicações, a construção das entidades da ciência no discurso; a recontextualização de conhecimento e a atribuição de significação ao que é material, através de demonstrações. O potencial destes resultados é discutido no contexto de investigações em desenvolvimento.

\section{Abstract}

This paper presents and discusses a theoretical framework for describing explanation in the science classroom. The proposed categories are based upon theoretical analyses of studies in Science Education, Linguistics, and Cognitive Science and on empirical investigations which involved the observation of secondary school science lessons in the London área. The result is a language of description of explanatory episodes which discusses: the creation of differences to motivate explanations, the construction of the entities of science in discourse; re-contextualisations of knowledge and; how demonstration puts meaning into matter. The potential of these results is discussed in the context of ongoing investigations.

\footnotetext{
${ }^{1}$ Colégio Técnico, UFMG

${ }^{2}$ School of Education, University of Sussex

${ }^{3}$ Institute of Education, University of London
} 


\section{EXPLICAÇÕES, CIÊNCIAS E SALA DE AULA}

Por que um navio flutua, se os metais afundam na água? Como é que o gás entra dentro do refrigerante? O que é que mantém a Lua girando em torno da Terra? Esses são exemplos de questões tipicamente encontradas nos livros e discutidas nas salas de aula de ciências e que necessitam de explicação. Embora haja quase um consenso de que explicar é, possivelmente, a tarefa mais fundamental de um professor de ciências, há dúvidas a respeito do que constitui uma boa explicação. Uma explicação que satisfaz o professor, muitas vezes, contraria as ideias que os estudantes têm a respeito do mundo físico. Uma explicação baseada no senso comum freqüentemente não encontra paralelo na visão correntemente aceita pêlos cientistas. E o trabalho diário na sala de aula é tentar estabelecer nexos, continuidades, relações entre essas diferentes visões de mundo e aproximar posições que se encontram separadas por abismos conceituais.

Parte da dificuldade na explicação de conceitos científicos advém do fato de que aprender ciências envolve não só alargar os horizontes da percepção e adquirir novos conhecimentos e informações mas, principalmente, passar a conceber o mundo físico de forma diferente e vislumbrar outras dimensões da relação entre o homem e a natureza. Por exemplo: a matéria passa as ser vista como composta principalmente de espaço vazio; germes microscópicos, e não a chuva ou o vento frio, passa a ser a causa dos resfriados; a Terra, normalmente vista como o chão em relação ao qual nos movimentamos, passa a ser considerada como ativa e em constante movimento; a gravidade transforma-se em espaço curvo; a luz ora se comporta como onda, ora como partícula. Aprender ciências é, portanto, aprender a ver o mundo de outras maneiras, algumas totalmente não intuitivas. Explicar envolve, ainda, além de uma análise cuidadosa dos conteúdos a serem tratados, considerar diferentes estratégias de comunicação, diferentes interesses e habilidades cognitivas dos interlocutores, a motivação, os objetivos e papéis sociais dos participantes, as restrições impostas pelo contexto, etc.

A despeito do papel crucial das explicações na comunicação da ciência a audiências leigas, não se vem tratando o tópico explicação como objeto de investigação sistemática na área de ensino de ciências. Neste artigo, apresentamos, de forma condensada, as bases de uma linguagem de descrição de episódios explicativos típicos da sala de aula de ciências. Essa linguagem relaciona categorias que estão fundamentadas numa sólida base teórica e em investigações empíricas de forma a permitir analisar, descrever, discutir e comparar situações reais.

\section{O problema de pesquisa}

É curioso, senão surpreendente, que o tema "explicações" não venha sendo objeto de estudo ou investigação sistemática na área de Ensino de Ciências. Da mesma forma, a atividade de 'explicar' não vem sendo tratada como algo que possa ser entendido, aprendido ou ensinado. Esses fatos acarretam graves consequências cujo impacto se faz sentir nas salas de aula. Por exemplo, as implicações para a formação (inicial e em serviço) de professores de ciências são evidentes. Como não há investigação sistemática nem análise do que está envolvido na tarefa de 'explicar', a experiência pessoal e o exemplo de colegas mais experientes tornam-se os únicos "professores" possíveis para aqueles que se iniciam na profissão. De fato, conhecemos muito pouco a respeito do processo de aprender através de "exemplo" e, sem evidências nas quais se possam basear argumentos acerca de como 
melhor explicar determinado conceito, fica-se restrito, quase que exclusivamente, ao nível da troca de experiências pontuais. Este trabalho surge, portanto, da necessidade de uma teoria, de uma linguagem, que seja compartilhada e que dê conta de descrever, analisar e iluminar o que está envolvido na tarefa de "explicar" e que ajude a caracterizar as explicações em termos de distinções mais informativas do que simples ou complicado, claro ou confuso, fácil ou difícil.

Essa linguagem também se faz necessária na tentativa de discutir colocações propostas* $^{*}$ pelas ciências cognitivas, pela filosofia, psicologia, linguística e análise do discurso, áreas nas quais encontramos discussões mais amplas sobre o tópico explicações. Estas apontam para aspectos fundamentais como a natureza das relações causais entre fenómenos, o impacto dos papéis sociais dos participantes, a influência do contexto, a dinâmica e a lógica de argumentação, etc. Contudo, a síntese dessas abordagens e a utilização de resultados obtidos no âmbito de uma disciplina, para iluminar discussões correlatas em outra disciplina ou em um contexto aplicado, não é tarefa trivial, principalmente na ausência de uma linguagem que medeie esses relatos e relacione esses resultados.

O objetivo da investigação aqui relatada foi propor uma linguagem, que permite não só a descrição mas também a comparação entre diferentes episódios explicativos nas salas de aula. A principal contribuição dessa linguagem pode ser entendida através de dois resultados. Por um lado, ela proporciona diferentes possibilidades de se pensar em como explicar diferentes tópicos e ideias científicas - como, por exemplo, as configurações eletrônicas ou a natureza do som - formuladas de maneira que permitam comparação e contraste, levando professores a adquirirem novos instrumentos e recursos para refletir e compreender o que acontece nas suas salas de aula. Por outro, ela proporciona estabelecer nexos entre o trabalho específico de explicar ciências na sala de aula e problemas mais gerais de comunicação. Explicar ciências pode, agora, ser enxergado numa perspectiva mais ampla que leva em consideração: (i) como as entidades das ciências são construídas no discurso e (ii) como linguagem, açào, gestos, relações pessoais se integram em atos de comunicação. Isso significa repensar teorias de comunicação de forma a acomodar o fato de que entender ciências não é somente entender o significado de certas palavras mas de objetos e eventos e suas ações no mundo real.

\section{ALGUNS PONTOS DE PARTIDA}

Recentemente, tem-se prestado muita atenção na "linguagem da ciência". Por exemplo, Hailiday e Martin (1992) ilustram, com eloquência, como a comunicação das ideias científicas faz uso de algumas estruturas como, por exemplo, a metáfora gramatical ${ }^{1}$, e discutem suas consequências para um entendimento conceituai do conhecimento científico. Para alguns autores, aprender ciências significa se apropriar do discurso científico, isto é, aprender determinados termos e como eles se relacionam através da identificação de padrões temáticos e da percepção das relações semânticas entre termos (Lemke, 1992). Já outros autores, como Edwards e Mercer (1987), falam claramente de como a linguagem é somente parte dos recursos de comunicação na sala de aula, concentrando sua discussão na negociação de significações compartilhadas, 
Nossa opinião é que as dificuldades do aprendizado de ciências transcendem os problemas advindos das tentativas de apropriação da chamada "linguagem da ciência". Para nós, aprender ciências significa, principalmente, considerar alternativas radicalmente novas de conceber o mundo. Em sala de aula, isso é feito através de estratégias que necessariamente empregam uma pluralidade de meios de comunicação de forma coordenada. Nessa perspectiva, a construção de novas significações não é vista como exclusivamente dependente da linguagem (escrita ou falada), mas como resultado da interação entre diversos sistemas de representação que incluem imagens, gráficos e diagramas, passando pelo uso de gestos e atividade física como, por exemplo, observação e manipulação de objetos o que, hoje em dia, acontece presencialmente ou mediado por novas tecnologias em comunicação eletrônica (Kress, Martins, Ogborn e McGillicuddy, 1997).

Ainda com relação ao trabalho de Edwards and Mercer, nós pro-blematizamos tamb' em a ideia da negociação entre professores e alunos com o objetivo de alcançar um estágio onde o conhecimento seja compartilhado. Embora concordando com a ideia de troca entre os participantes através de um esforço mútuo de compreensão, reconhecemos que a relação entre professor e aluno é assimétrica e obedece às restrições e aos objetivos do currículo o qual determina não somente pontos de chegada mas também caminhos para alcançar os últimos. Estudos sobre explicações no discurso (Antaki 1988, 1992) fornecem evidências de que dificilmente é possível isolar "sentenças explicativas". Mais ainda, esses estudos revelam que marcadores léxicos como, por exemplo, porque ou portanto não são indicadores confiáveis da presença de uma explicação. Isso nos leva a uma visão de explicação como uma propriedade emergente ${ }^{2}$ do discurso. Nessa perspectiva, em nossas investigações trabalhamos com o conceito de ' episódio explicativo' e não 1. O conceito de metáfora gramatical desenvolvido por Hailiday e Martin (1992) se refere ao processo no qual uma classe gramatical é substituída por outra. Por exemplo "a mudança de direção de propagação da luz quando esta entra num meio material transparente como ar ou água é chamada refração". Um processo torna-se um substantivo, caracterizando uma nova entidade -refração - que, daí em diante, passa a se relacionar com outras entidades (ex. reflexão, etc.) tomando parte em novas redes de significações.

Com a idéia de 'sentença explicativa' . Um 'iséfolio explicativo' relaciona participantes que atuam em um cenário e se estende ao longo do tempo, possuindo uma estrutura inclusiva em que um episódio pode conter outros episódios ou subepisódios.

No que diz respeito à natureza da comunicação em sala de aula, essa é vista como essencialmente e continuamente ativa, trans-formativa e construtiva (Hailiday, 1985). Consideramos que cada significação construída é, de alguma forma, uma nova significação, isto é, aqueles que buscam compreender algo têm que, necessariamente, re-criar significações para si próprios (Hodge and Kress, 1988). Também consideramos a comunicação como envolvendo a integração de vários sistemas de representação com características diferentes (Kress and van Leeuwen, 1996). No passado, e ainda hoje em dia, a tradição da cultura ocidental privilegia a linguagem e, em particular, a linguagem escrita sobre a falada, como meio principal de comunicação. Outros meios como gráficos e imagens são frequentemente considerados como adjuntos ou, até mesmo, subordinados à linguagem. Nós acreditamos que é necessário considerar outros meios e sistemas de representação, tais como gestos e ações, já que a comunicação envolve todos eles de forma integral e articulada. 
Dentro da filosofia da ciência, uma visão particularmente atraente é a de autores como Harré e Bhaskar (Marre and Madden 1977, Bhaskar 1978, Harré 1986, Hanson 1958, 1972) que discutem explicações em termos da ontologia das entidades envolvidas nos fenómenos a serem explicados. São as propriedades, tendências e os "poderes" dessas entidades que produzem os fenómenos. Dentro dessa perspectiva, explicações deixam de ser ' sentenças' deduzidas a partir de leis gerais, passando a adquirir um caráter de necessidade num determinado contexto. Essa concepção abre espaço para a discussão do papel de metáforas e analogias nas explicações científicas.

Investigações acerca das categorias básicas utilizadas pelas pessoas na organização da experiência têm sido objeto de estudo de linguistas e psicólogos e são de particular relevância aqui. O conceito de raciocínio prototípico, proposto por Rosch (Rosch e Lloyd 1978) e desenvolvido por Lakoff (Lakoff 1987, Lakoff e Johnson 1983, Johnson 1987) é especialmente importante e sugestivo. De acordo com essa visão, explicações se baseiam em julgamentos ontológicos de similaridade e diferença. Em nossos próprios estudos (Ogborn e Martins, 1996, Martins e Ogborn 1997), essa ideia foi explorada em investigações acerca da compreensão de metáforas comumente utilizadas no ensino de ciências. Metáforas estão na raiz da nossa conceitualização e entendimento do mundo físico e são um fenómeno de cognição e não somente um fenómeno linguístico ou de comunicação (Lakoff e Johnson, 1983). Outra influência marcante aparece na forma de estudos que revelam a existência de um pequeno número de dimensões, consistentemente utilizadas por estudantes para caracterizar entidades (energia, vírus, força, etc.) e eventos (uma reação química, movimento de satélites, etc) (Mariani e Ogborn, 1995). Essas investigações, fortemente influenciadas pelas ideias de Piaget e Garcia (1987), discutem como significações para novas entidades são construídas através da ação, a partir de análises (a) do que estas entidades podem fazer, (b) do que pode ser feito a elas e (c) do que elas são feitas.

Existe, ainda, dentro da Ciência Cognitiva, uma visão que guarda paralelos com a visão exposta acima. As ideias de Roger Schank $(1977,1986)$ e as estruturas por ele propostas (scripts, MOPS, etc) introduzem uma dimensão dinâmica quando relaciona a necessidade de explicarmos algo ao nosso grau de entendimento dos fenómenos, por exemplo, quando somos surpreendidos por fatos que contrariam nossas expectativas.

Em resumo, colocamos aqui diversas escolhas e suposições acerca da natureza do processo de comunicação em geral e das explicações científicas bem como as relações entre diversos sistemas de representação e entre diversas disciplinas científicas. Preferimos pensar nas explicações como envolvendo a criação de novas visões de mundo, onde possam existir novas entidades constituintes e participantes de novas realidades, que possuem possibilidades de ação e interação próprias em sequências de eventos. Uma explicação nos diz como essas entidades atuam juntas de forma a produzirem fenómenos. Explicações, portanto, baseiam-se na natureza básica, na ontologia das entidades físicas, abrindo espaço para uma discussão acerca do uso de metáforas e analogias nas explicações científicas. Contribuições importantes que iluminam essa discussão são os estudos sobre categorização do mundo físico, que sugerem que os princípios de categorização estão apoiados na percepção de similaridades e na identificação de protótipos e não na verificação de condições necessárias e suficientes como critérios de inclusão numa determinada classe. 


\section{O MODELO PROPOSTO: EXPLICANDO UMA EXPLICAÇÃO}

O desenvolvimento da linguagem de descrição para episódios explicativos, aqui descrita, deu-se a partir do trabalho do projeto Explanation in the Science Classroom e envolveu observações de sala de aula, durante um período de, aproximadamente, 12 meses. Contando com a ajuda de doze professores (sete do sexo masculino e cinco do sexo feminino) em quatro escolas secundárias de Londres, foram gravadas, em vídeo, 52 horas de aulas para estudantes de 11 a 16 anos,que incluíam tópicos de Física, Química, Biologia e fundamentos de Geologia. As aulas foram posteriormente transcritas na íntegra, englobando referências à comunicação não verbal, tais como desenhos e gestos, manipulação de equipamento, uso de recursos visuais, fortemente presente nas interações observadas. O tratamento dos dados envolveu assistir e discutir os vídeos e transcrições de forma a desenvolver perspectivas em relação às quais pudéssemos analisá-las. Nosso esforço foi, portanto, direcionado à identificação de categorias adequadas que descrevessem as interações observadas, não a uma análise exaustiva de todos os dados. O resultado é a linguagem de descrição apresentada a seguir, desenvolvida com base em análises de contribuições teóricas relacionadas na seção anterior e associadas a resultados dessas investigações empíricas, que envolveram observação em salas de aula de ciências.

Nesta seção descrevemos, em linhas gerais, categorias propostas com o intuito de oferecer uma alternativa para pensar sobre explicações, como elas transformam o conhecimento para diferentes audiências e os diferentes 'estilos' nos quais é possível explicar. O modelo desenvolvido, discutido de forma estendida no livro Explaining Science in the Classroom (Ogborn, Kress, Martins e McGillicuddy, 1996), apresenta dois eixos:

- A discussão de como explicações científicas podem ser entendidas como análogas a estórias.

- A discussão de que explicar envolve quatro momentos: criar "diferenças", construir "entidades", transformar conhecimento e atribuir significação ao que é material.

Essa discussão leva, ainda, em consideração fatores que podem constituir fontes de variação nos episódios explicativos, tais como: estruturas explicativas inclusivas, aspectos do conteúdo a ser tratado, características do professor e sua história de interação com os estudantes. Mostramos, ainda, como as categorias acima compõem possibilidades de caracterização e análise de situações de sala aula e ajudam a caracterizar alguns estilos como: ' vamos pensar juntos' , ' o contador de estórias' , ' repita comigo' e ' veja sob meu ponto de vista' .

\section{EXPLICAÇÕES CIENTÍFICAS E ESTÓRIAS}

Vemos nas explicações científicas uma estrutura análoga à das estórias. Isso pressupõe imaginar um elenco de protagonistas, caracterizados por suas habilidades e especificidades os quais, juntos, tomam parte em uma série de eventos, cujo desenrolar e cujas consequências derivam da natureza desses protagonistas. Existe, portanto, um mundo de protagonistas (elétrons, genes, etc.) que têm poderes próprios de ação e que interagem em sequências de eventos (uma corrente elétrica flui, proteínas são formadas, etc.). 0 resultado é o fenómeno a ser explicado (uma lâmpada acende, uma célula se desenvolve, 
etc.). O objetivo dessa analogia é mostrar que, em ciências, nenhum desses componentes pode ser simplesmente assumido como não problemático. O grau de familiaridade com essas entidades, com o que elas fazem e com o que podemos fazer com elas varia, caracterizando e motivando diferentes possibilidades de entendimento. Vejamos alguns exemplos que mostram como uma estória relaciona eventos de forma não arbitrária, já que esses acontecem por causa das propriedades e da natureza das entidades nela envolvidas. Pode-se explicar a poluição num rio como resultado do acúmulo e consequente decomposição de matéria orgânica, acelerada pela ação de fertilizantes levados das plantações até o rio pela chuva. Nesse caso, a maiffria dos personagens, bem como os mecanismos através dos quais eles atuam (água que transporta materiais, fertilizantes que fazem plantas crescerem, etc.), é razoavelmente conhecida. Já uma explicação da origem do carvão, por exemplo, embora envolvendo cenários não muito distantes do senso comum (florestas tropicais, vegetação em decomposição, efeitos de condições extremas de temperatura e pressão, etc) faz referência a uma escala de tempo fora de qualquer experiência possível e estabelece conexões com outras estórias, que não são tão próprias do senso comum (deriva continental, dobras em rochas, etc.).

Explicações sobre a transmissão de doenças ou sobre o mecanismo de hereditariedade requerem aceitar a existência de um mundo tão real como o mundo macroscópico do nosso cotidiano, no qual existem novas entidades com novos comportamentos e novas possibilidades de ação só que numa escala muito pequena para que possamos agir diretamente sobre elas. Possuir cabelos castanhos ou olhos azuis passa a ser possuir um determinado conjunto de sequências de ADN quimicamente codificadas. Aqui, as estórias envolvem objetos, que não nos são familiares, e que realizam ações, as quais também não são triviais, num mundo ou cenário inacessível.

E o que dizer sobre campos elétricos e campos magnéticos, levando noticiários e novelas até nossas casas, ao explicarmos o funcionamento de uma televisão? Não é, de modo algum, trivial entender como "uma região do espaço onde uma força pode agir sobre uma partícula" pode ir de um estúdio até nossas casas e que, para trabalharmos a existência real dos campos, precisamos também caracterizá-los como algo que existe como construção mental.

A existência de uma explicação também faz diferença no que diz respeito ao que é um fenómeno. Pensar numa cadeia de montanhas que divide dois países é totalmente diferente de pensar nessas mesmas montanhas como um caso da crosta terrestre "sendo dobrada". É a existência da explicação que dirige nossa atenção para o que é relevante e para como o mundo deve passar a ser visto.

Outra característica importante é que as explicações cientificas tratam eventos estranhos como óbvios, isto é, elas modificam a percepção do que é óbvio. Se uma pessoa ' pegou' um resfriado, é porque ela foi infectada e não porque ela ' apanhou' chuva ou andou descalça num dia frio. Após Newton, tornou-se "óbvio" que a Terra se move em torno do Sol sem que nenhuma força esteja aluando na direção do movimento. Contudo, até os dias de hoje, o raciocínio do senso comum ' estranha' a possibilidade de um objeto se mover livre de forças. 


\section{EXPLICAÇÕES ENVOLVEM:}

\section{Criar 'diferenças'}

$\mathrm{Na}$ maioria das situações do nosso dia-a-dia, as explicações surgem a partir de pedidos de informação. Na sala de aula, ao contrário, explicações são oferecidas. O estudante é colocado, na maioria das vezes, numa posição de quem necessita de informação ou conhecimento. E esse conhecimento não é determinado pelo estudante, mas por programas curriculares. É importante, portanto, falar de como os professores motivam explicações nas suas salas de aula, um contexto que, ao contrário do que acontece no diaa-dia, é socialmente definido de tal forma a permitir que explicações que não foram solicitadas pelo alunos sejam oferecidas. Em termos de comunicação, isso envolve criar uma "diferença" entre as partes. Assim, existem diferenças entre o que o estudante sabe e o que o estudante deve saber. Ou ainda, diferenças entre o que o estudante deve saber e o que o estudante quer saber. Essas diferenças, que podem ser caracterizadas em termos de interesse, conhecimento, opinião, etc., devem ser exploradas para que seja possível resolvê-las e permitir que dois pontos de vista, inicialmente incompatíveis, sejam aproximados. Maneiras de criar diferenças envolvem promessas de futura utilidade do conhecimento em questão, exploração de fenómenos não intuitivos, expectativas não concretizadas.

Uma classe importante de diferença é a diferença entre o conhecimento científico e o conhecimento do senso comum. Explicações científicas geralmente são formuladas em termos de entidades que não são familiares aos estudantes, as quais se comportam de maneira estranha num mundo distante. Isso acontece, em parte, porque explicações na sala de aula são, frequentemente, determinadas pelas explicações científicas disponíveis. Assim, o aluno não vê sentido em ter que explicar a rigidez dos sólidos. No entanto, essa questão é colocada por professores pois estes têm uma estória interessante para contar acerca do espaço vazio entre os átomos.

\section{Construir entidades}

Antes que uma estória acerca de determinado fenómeno possa ser contada na sala de aula, é preciso construir os recursos que serão utilizados nesse processo. Por exemplo, antes de estarmos aptos a dizer algo sobre o brilho das lâmpadas num circuito, precisamos falar sobre correntes elétricas, voltagens, resistências, etc. Contudo os protagonistas dessas estórias frequentemente são desconhecidos para os alunos. Átomos, pontos materiais, ondas, genes e outras entidades da ciência precisam ser construídos, no discurso da sala de aula, como coisas a serem entendidas, objetos sobre os quais devemos pensar. À medida que a escolarização progride, muitas entidades científicas passam, de objetos de reflexão e análise, a ferramentas para o pensamento, transformando-se em parte das explicações e não permanecendo como coisas a serem explicadas. Dessa forma, a construção das "entidades" é também a construção de futuras explicações.

A variedade de entidades a ser explicada é grande. Algumas são invisíveis ou intangíveis (por exemplo, micróbios e ondas), outras são padrões (como a tabela periódica), outras ainda são abstraias (como, por exemplo, uma senóide). Elas podem ser objetos (átomos), instrumentos (osciloscópios), processos (fusão), relações (Lei de Ohm), classificações (gás ou fluido), etc. A todas, chamamos entidades por duas razões principais. Primeiramente, porque, apesar das diferenças, todas são introduzidas tanto no discurso 
científico quanto no discurso da sala de aula de uma forma que parece muito semelhante: como coisas sobre as quais ou com as quais pensamos. A outra razão é que seus significados são construídos a partir de análises do que elas são feitas, do que elas fazem e do que se pode fazer a elas.

\section{Transformar o conhecimento}

O conhecimento científico não é estático e é continuamente transformado de forma a se tornar mais acessível a diferentes audiências. Dos manuscritos originais até livros-texto utilizados na escola secundária ou para divulgação científica, várias transformações acontecem. Ao mesmo tempo, avanços tecnológicos também proporcionam uma percepção da ciência e da própria tecnologia através de seus artefatos, sem que isso necessariamente passe pela escola. Exemplos vão da luz elétrica nas casas à proliferação de computadores pessoais.

O conhecimento não só sofre diversas transformações até chegar à escola mas também é continuamente transformado na escola. Uma maneira de se transformar dado conhecimento é torná-lo uma narrativa. Estórias, seja da descoberta da penicilina ou um relato de experiência pessoal - como descobrir que o leite azedou - agem de maneira eficiente como um veículo para o conhecimento. As relações entre personagens e eventos numa narrativa correspondem às relações conceituais a serem entendidas, e fazem com que estas últimas sejam memoriáveis e facilmente lembradas. $O$ uso de metáforas e analogias também é crucial na transformação do conhecimento. Em nossas observações, registramos exemplos que incluem o olho humano visto como uma câmera fotográfica e a glândula pituitária como um maestro conduzindo uma orquestra. $\mathrm{O}$ trabalho recente de Sutton (1992) revela a origem metafórica de termos sobre a qual, hoje em dia, não nos perguntamos mais, caracterizando esses termos como interpretações ativas e não apenas como rótulos passivos ${ }^{3}$. Metáforas, portanto, são vistas não como imagens acessórias mas como fundamentais para a linguagem, na medida em que significações são construídas a partir de outras significações que, em última análise, encontram-se ancoradas em ações no mundo.

\section{Atribuir significação ao que é material}

As teorias científicas pretendem descrever o mundo "como ele realmente é". Contudo, o mundo não se mostra nada parecido com o que essas teorias nos dizem. A energia parece não se conservar, o movimento não parece continuar na ausência de forças, o ar não parece ter peso, etc. As teorias científicas falam do mundo "por trás das aparências" e as demonstrações tentam trazer esse mundo subjacente à superfície. A função de uma demonstração é levar os estudantes a ver as coisas como as teorias dizem que elas são: demonstrações têm a ver com "passar a ver o mundo de uma certa forma". O som é para ser visto (e pensado) como uma onda; eletrólise, como o fluxo de partículas carregadas; etc. E o propósito das demonstrações é mostrar que é assim que essas coisas realmente são, isto é, que não se trata somente de se ver o som como onda, mas de considerar que o som é uma onda. Demonstrações, portanto, ajudam a revelar como o comportamento do que é material impõe restrições acerca do que podemos ou não imaginar. 


\section{Fontes de variação}

O que nós fizemos até agora foi discutir dimensões ao longo das quais é possível descrever e comparar explicações e não discutir e identificar diferentes tipos de explicação. De fato, uma dada explicação relaciona vários dos aspectos discutidos acima ao mesmo tempo (embora não necessariamente na ordem apresentada), orquestrados de uma maneira particular, combinados como numa canção, onde melodia, harmonia e ritmo formam um todo. Raramente, explicações são eventos isolados. Elas se organizam em estruturas que se complementam e formam outras explicações. Outra fonte de variação é o professor, sua história pessoal, sua bagagem de recursos, experiência de sala de aula, etc. A interação com os alunos também vai determinar possibilidades de explicação, na medida em que estes solicitam e respondem de maneira diferenciada, influenciando, dessa forma, as escolhas do professor. A matéria a ser explicada também determina o que deve ser assumido e o que deve ser evitado. As decisões dependem de as entidades envolvidas serem objetos ou processos; serem abstra-tas ou concretas; serem naturais ou artificiais.

\section{Estilos}

Diferentes professores irão combinar esses aspectos de diferentes maneiras. "Contadores de estórias" constróem explicações utilizando narrativas clássicas de descobertas científicas como Newton e a maçã, Kekulé e seu sonho, Fleming e a descoberta acidental da penicilina. Alguns chegam até uma explicação que molda, reformula e parafraseia contribuições recebidas de seus estudantes num contínuo ir e vir entre aceitar contribuição dos estudantes e transformá-las em versões ' definitivas' . Outros, ainda, colocam a ênfase na maneira de colocar ideias através de palavras ou ex- pressões que são repetidas e praticadas, derivando explicações dos papéis gramaticais desempenhados pêlos termos (por exemplo, numa sentença como: "A energia faz com que ele atinja uma distância maior", ' energia' é tratada como um agente causal ató). Finalmente, muitas explicações científicas exigem que o professor tente persuadir o estudante a re-conceber, a ver o mundo a sua volta à luz de determinada teoria (como passar a pensar a Terra em movimento e não como o chão onde nos movimentamos).

\section{DESDOBRAMENTOS E IMPLICAÇÕES}

\section{Investigações, empíricas em desenvolvimento}

Como foi dito, essa linguagem levanta as principais dimensões a-través das quais julgamos ser possível descrever episódios explicativos na sala de aula de ciências. É crucial para o desenvolvimento do modelo proposto, no entanto, submetê-lo ao escrutínio de professores, investigando como ele é entendido e como pode ser u-tilizado pêlos mesmos. Espera-se, com isso, alcançar uma visão mais detalhada e crítica do real potencial dessa linguagem de descrição, para ajudar os professores a reconhecer o que eles estão fazendo, para ajudá-los a considerar alternativas e a reconhecer elementos presentes e ausentes que poderiam estar afetando seu desempenho.

Investigações em desenvolvimento têm explorado, em que medida, especificidades de alguns contextos educacionais podem esclarecer ou revelar aspectos relevantes para a análise de explicações. Por exemplo, qual a importância e as funções que metáforas, analogias e outros recursos de imaginação possuem em situações de ensino nas quais a 
ênfase nas atividades práticas e de laboratório não é tão acentuada quanto nas salas de aula no Reino Unido.

É também crucial saber em que medida uma linguagem de descrição auxilia professores a refletir sobre sua prática, criando alternativas para serem trabalhadas em sala de aula. O modelo proposto possui componentes bem definidos que podem ser trabalhados tanto em nível da formação inicial quanto em cursos de capacitação de professores em serviço. Por exemplo, é possível explorar as possibilidades de dois estilos de explicação para tratar o mesmo conteúdo, ou elaborar sequências instrucionais que envolvam explicações em diferentes níveis de complexidade e generalização, A analogia entre explicações científicas e estórias, originalmente proposta por Ogborn (1994), tem também inspirado recomendações acerca de como o conhecimento científico deve ser apresentado em programas curriculares (Miliar e Osborne, 1998). Investigações em andamento discutem o potencial explicativo de narrativas clássicas da ciência em situações de sala de aula (Ribeiro e Martins, 1998).

Outro desdobramento importante é a adaptação e utilização de categorias relacionadas nessa linguagem de descrição para análise de situações de sala de aula bem como de textos didáticos, permitindo a caracterização de diferentes retóricas do ensino de ciências (Martins, 199^-6; Kress, Ogborn, Jewitt e Tsatsarelis, 1998).

Finalmente, essa linguagem também não nos informa a respeito de como os estudantes recebem determinadas explicações. É preciso identificar o que, para eles, conta como uma explicação efetiva. Isso aponta na direção de problematizarmos a linguagem de descrição de forma a torná-la mais apta para a descrição de interações entre estudantes. Deseja-se, com isso, obter parâmetros para a construção de testes, de forma a se conseguirem indicadores dos diferentes tipos de entendimento que uma determinada explicação pode ter ajudado a produzir.

\section{CONCLUSÕES}

O trabalho aqui descrito contém duas dimensões bem definidas: uma teórica e uma aplicada. Ele oferece uma nova perspectiva metodológica na investigação da comunicação do conhecimento científico na sala de aula, problematizando a suposição de que a linguagem verbal desempenha um papel principal nesse processo. Ao mesmo tempo, ele sugere um conjunto de categorias básicas que pode ser utilizado na análise e na descrição de funções da explicação na sala de aula e nos livros didáticos.

O modelo proposto também permite re-conceber o binómio ensino-aprendizagem no contexto de tendências modernas de programas curriculares, pois, além de desenvolver o conhecimento do aluno, valorizar o despertar do interesse e entusiasmo do mesmo pela ciência bem como a percepção de suas inter-relações com outras instituições sociais e com a tecnologia.

Outro ponto importante diz respeito a trabalhar contribuições das áreas de Ensino de Ciências e Semiótica em investigações acerca da construção de significados no aprendizado de ciências. Afinal, explicar conceitos científicos na sala de aula envolve tanto entender o conteúdo dessas explicações quanto ser capaz de comunicar esse conteúdo de maneira efetiva. $\mathrm{Na}$ investigação de problemas relacionados à leitura, compreensão e expressão de ideias científicas sempre existe o perigo de as pessoas da área de ensino de ciências utilizarem um modelo muito limitado de comunicação. Linguistas e semiologistas, 
no entanto, nem sempre percebem as consequências de certas particularidades da organização e estruturação do conhecimento científico na maneira como ele é comunicado. A perspectiva através da qual temos trabalhado, e pretendemos continuar trabalhando, não tenta simplesmente aproximar dois pontos de vista aparentemente distantes. Nosso principal objetivo é fazer com que esses dois sistemas possam interagir e alcançar uma síntese que não pode ser atingida, de modo independente, por nenhum deles isoladamente.

\section{Agradecimentos}

Os autores agradecem o apoio do Economic and Social Research Council (ESRC) no Reino Unido ao projeto Explanation in the Science Classroom (R000234916). Os autores destacam, também, a contribuição de Kieran McGillucuddy que, embora não tendo participado, particularmente, da elaboração deste artigo contribuiu, de forma significativa, com idéias originais e análises críticas para o desenvolvimento do trabalho aqui relatado.

\section{REFERÊNCIAS}

ANTAKI, C. (1992) Expiaining and Arguing. Londres: Sage.

ANTAKI, C (Ed.) (1988). Analysing everyday explanation. Londres: Sage.

BHASKAR, R (1978) A realist view of science. New Jersey: Hassocks.

EDWARDS, D. and MERCER, N. (1987) Common Knowledge; The Development of Understanding in the Classroom. Londres: Methuen/Routledge.

HALLIDAY, M, A. K. and MARTIN, J. (1992) Writing Science; Literacy and Discursive Power. Londres: Falmer Press.

HALLIDAY, M. (1978) Language as Social Semiotic. Londres: Arnold.

HANSON, N. (1958) Patterns of Discovery. Londres: Allen and Unwin. HANSON, N (1972) Observation and explanatíon. Londres: Allen and Unwin.

HARRÉ R (1986) Varieties of Ftealism. Oxford: Blackwell

HARRÉ e MADDEN (1977) Causal Powers. Oxford : Blackwell.

HODGE, R. and KRESS, G. R. (1988) Language as ideology.Londres: Routiedge.

JOHNSON, M. (1987) The Body in the Mind. Chicago: Univ. of Chicago Press.

KRESS, G. and van LEEUWEN. T. (1996) fíeading Images; the grammar of visual design. Londres: Routiedge 
KRESS, G.; MARTINS, I.; OGBORN, J.; MCGILLICUDDY, K. (1995) Visual Communicafion in the Learning of Science. An $\mathrm{n}$ uai Meeting of the European Science Education Research Association, 1, Roma.

KRESS, G.; OGBORN, J.; JEWITT, C. e TSATSARELIS, C. (1998) Multi-modai rhetorics of the science classroom. Pre-print, Institute of Education University of London.

LAKOFF, G. (1987) Women, fire and dangerous íhings; what categories reveal about the mind University of Chicago Press.

LAKOFF, G. e JOHNSON, M. (1983) Metaphors we live by. Chicago: University of Chicago Press.

LEMKE, J. (1992) Taiking Science. Nova lorque: Ablex.

MARIANI, M. C., OGBORN, J. (1995) The ontology of physical events; a comparison of two groups. Internaíional Journal of Science Education, 17 (5), 643-661.

MARTINS, I.; OGBORN, J. (1997) Metaphorical reasoning about genetics. International Journal of Science Education, vol.19,?1, 47-63.

MARTINS, I. (1998) Retórica e ensino de ciências? Encontro de Pesquisa em Ensino de Física, 6, Florianópolis, SC: Atas do VI EPEF.

MILLAR, R. eOSBORNE.J. (1998) Beyond 2000. King's College London: School of Education (também disponível na URL http://www.kcl.ac.uk/education).

OGBORN, J. (1994) Theoreticai and empirical investigations of the nature of scientific and common-sense knowledge. Londres: Univertsity of London. (Doutorado).

OGBORN, J.; KRESS, G.; MARTINS, I.; MCGILLICUDDY, K. (1996) Expiaíning Science in the Classroom. Milton Keynes: Open University Press.

OGBORN. J.; MARTINS, I. (1996) Metaphorical understanding and scientific ideas. International Journal of Science Education, vol.18, No. 6, 631-652.

PIAGET, J.; GARCIA, R.; (1987) Vers une lógique dês significations. Genève: Murionde.

RIBEIRO, R. M. L.; e MARTINS, I. (1998) Uma análise de narrativas relacionadas à natureza e à história da ciência. Encontro de Pesquisa em Ensino de Física, 6, Florianópolis. Atas....

ROSCH, E.; LLOYD, B. B. (Eds) (1978) Cognition and categorization. Hilisdate, NJ: Lawrence Eribaum.

SCHANK, R. (1986) Explanation patterns. Hilisdate, NJ: Lawrence Eribaum. SCHANK, R.;

ABELSON, R.; (1977) Scripts, plans, goals and understanding. Hilisdate, NJ: Eribaum. 
SUTTON, C. (1992) Words, science and learning Buckingham;

\section{Correspondência:}

Profa. Isabel Martins, Setor de Física, Colégio Técnico, Universidade Federal de Minas Gerais, Av. António Carlos,6627, Belo Horizonte, MG - cep. 31270-900. Correio Eletrônico: isabel@coltec.ufmg.br

Submetido em 06/12/97, aceito para publicação em 03/12/98. 